\title{
BI-DIRECTIONAL DC- DC CONVERTERS FOR SUPERCAPACITOR BASED ENERGY BUFFER FOR ELECTRICAL GEN-SETS
}

\author{
Jan Leuchter ${ }^{1}$, Pavol Bauer ${ }^{2)}$, Petr Bojda ${ }^{3)}$, Vladimir Rerucha ${ }^{4)}$ \\ ${ }^{1,3,4)}$ UNIVERSITY OF DEFENCE, ${ }^{2}$ DELFT UNIVERSITY OF TECHNOLOGY \\ ${ }^{1,3,4)}$ Kounicova 65, Brno, 623 00, the Czech republic \\ Tel.: +420 / 973443660, 973445007, 973444333 \\ ${ }^{2)}$ Mekelweg 4, Delft, $2628 \mathrm{CD}$, the Netherlands \\ Tel.: $+310 / 152784654$ \\ E-Mail: Jan.Leuchter@unob.cz, P.Bauer@tudelft.nl,Petr.Bojda@unob.cz, Vladimir.Rerucha@unob.cz \\ URL: ${ }^{1,3,4}$ http://www.unob.cz, ${ }^{2}$ http://www.tudelft.nl
}

\section{Acknowledgements}

The research work is supported by the Grant Agency of the Czech Republic (project no. 105/05/P001) and Czech Ministry of Education, Youth and Sports (project no. OC169/COST542).

\section{Keywords}

Bi-directional Converters, DC-DC, Energy Buffer, Supercapacitors, Electrical GEN-SET, FPGA.

\begin{abstract}
The real drawback of the concept of electrical generator sets (EGS) with variable speed is the enginegenerator dynamics at sudden load change from low to high. The analysis of dynamic behavior presented in this paper proves that the disadvantageous dynamical properties of EGS concepts with variable speed of engine can be improved by using an energy storage element. This paper give results of design of the bi-directional dc-dc converters for energy buffer with supercapacitors and also demonstrates the results of dynamic behavior EGS with energy buffer.
\end{abstract}

\section{Introduction}

Contemporary trends of development in mobile electrical generator sets (EGS) show, that the future generation of EGS will be based on the optimum variable speed of a diesel or petrol engine to achieve higher efficiency. Mobile electrical GEN-SETs are used for machines and appliances to increase their mobility. A simplified block diagram of an EGS with variable speed engine concept can be seen on Fig. $1[1,3]$.

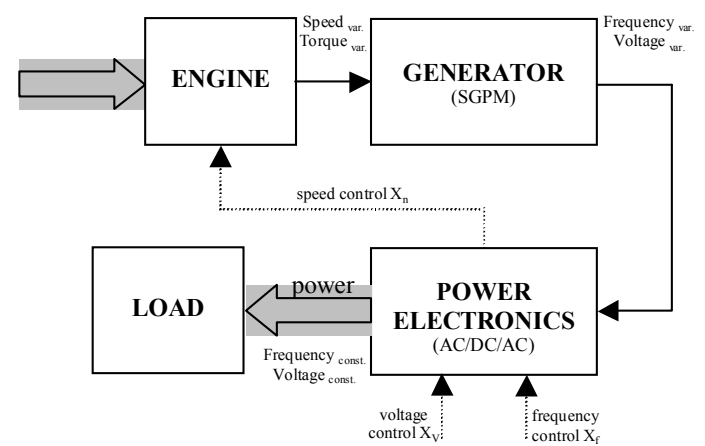

Fig. 1: Block diagram of an EGS system with variable speed of engine

The engine speed of rotation is to be optimally controlled in such a way as to adjust the operating regime for every load to the corresponding power output and torque with the minimum fuel consumption optimality criterion. 
The experimental model consists of the modern diesel engine with power output $7.7 \mathrm{~kW}$ for $3600 \mathrm{rpm}$ and $3.8 \mathrm{~kW}$ for $1500 \mathrm{rpm}$ and 12 poles of synchronous generator with permanent magnets (SGPM). The output voltage of generator is varying in the range from $150 \mathrm{~V}$ to $450 \mathrm{~V}$ at the frequency 100 to $300 \mathrm{~Hz}$. Power electronics that are set up from AC/DC, DC/DC and DC/DC converter (AC/DC/AC) convert output voltage of generator to the constant three-phase EGS output $(400 \mathrm{~V} / 50 \mathrm{~Hz})$. As mentioned above the real drawback of EGS with optimum variable speed is an engine-generator dynamics at sudden transient from low load to high load. More details about test and measurement of dynamic behavior were shown in [2]. In case of sudden power output increase, the engine can not deliver the requested torque and the result is further decrease of the speed and torque of the engine until the undesirable stop. Engine is namely not able to make sufficient torque and EGS source cannot deliver energy to the load. Problems of EGS behavior can be solved with speed higher than optimum speed is or the other concept is EGS using energy buffer. Fig. 2 shows concept EGS that is extended with energy buffer to achieve possibilities to operate with optimum speed for every load.

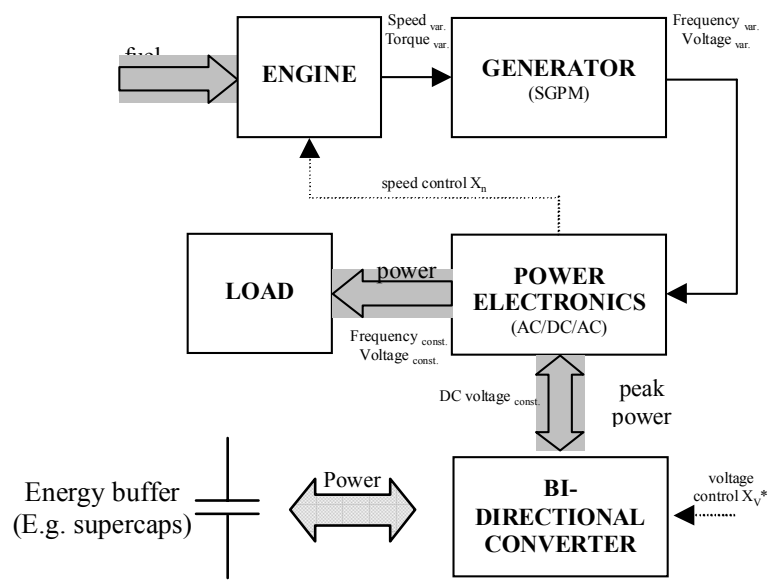

Fig. 2: Block diagram of an EGS with energy buffer

\section{The Configuration and Variation of Energy Buffer}

As mentioned above, the real drawback of EGS with optimum variable engine speed is the enginegenerator dynamics at sudden transients from low load to high load. The time of regulation is not higher than $2 \mathrm{~s}$ [4]. Electronic converter can improve the dynamic behavior by means of inserting accumulated energy to the voltage link of the DC/DC during the regulation of engine from low to high speed. The equation of storage energy $\mathrm{W}$ is given by power $P_{\max }$ and average time of regulation $T_{\text {reg }}$.

$$
W=P_{\max } \cdot T_{\operatorname{Re} g} \doteq 6000 \cdot 2=12 \mathrm{~kJ}
$$

Energy storage can be achieved by supercapacitors. Supercapacitor represents one of the newest innovations in the field of the electrical energy storage. Efficiency of charging and discharging is much higher than a solution with battery and can bring better relationship between stored energy, dimensions and weight then battery. If we compare $\mathrm{Wh} / \mathrm{kg}$, than battery will have cca 100 and supercapcitor only cca 10 , but if we concentrate on parameter $\mathrm{W} / \mathrm{kg}$ then supercapacitor will be $10 \mathrm{x}$ better [7]. Fig. 3 shows nominal voltage's influence on the value of output capacity of supercapacitor (modules BPAK0350-15) when delivering (to deliver) $6 \mathrm{~kW}$. Time $t$ shows how long we have energy for $6 \mathrm{~kW}$ EGS and $I$ is a current that will be possible to charge or discharge. The Fig. 3 illustrates that the nominal voltage $100 \mathrm{~V}$ can be optimum for our application and e.g. energy buffer with module BPAK0350-15 designed for $U_{\text {nom }}=105 \mathrm{~V}$ can store cca $34 \mathrm{~kJ}$ according to the formula (2) and can delivery $6 \mathrm{~kW}$ during $5 \mathrm{~s}$. That is enough for our application.

$$
W=\frac{1}{2} \cdot\left(C_{\text {cell }} \cdot \frac{\# \text { parallel }}{\# \text { series }}\right) \cdot\left(U_{\text {nom }}^{2}-\left(\frac{U_{\text {nom }}}{2}\right)^{2}\right)=\frac{1}{2} \cdot\left(58 \cdot \frac{1}{7}\right) \cdot\left(105^{2}-\left(\frac{105}{2}\right)^{2}\right)=34.3 \mathrm{~kJ}
$$




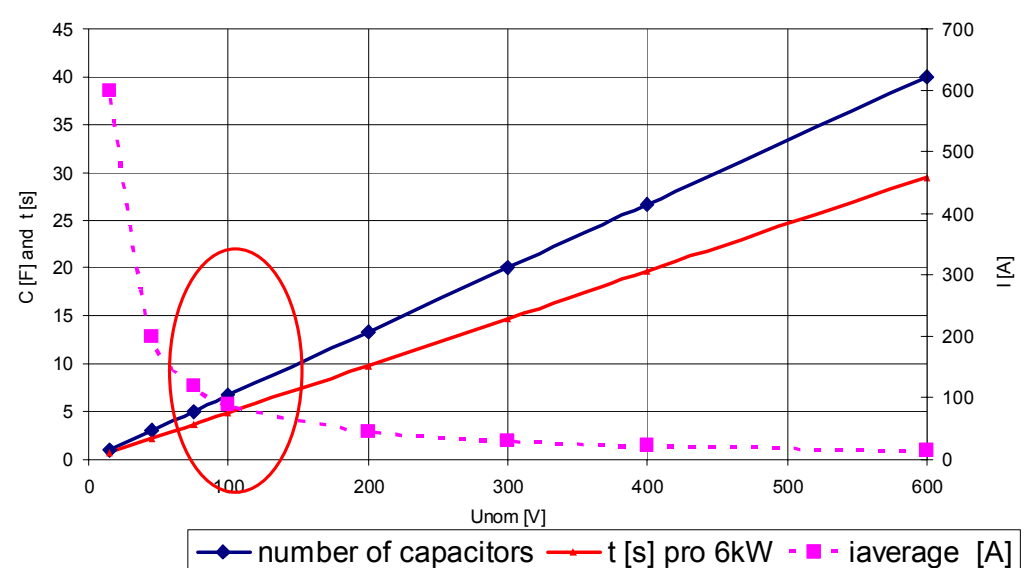

Fig. 3: Optimalisation of design nominal voltage of supercapacitors bank

The main disadvantage of high nominal voltage is high internal resistance $R_{i}$. The internal resistance of single module $(15 \mathrm{~V})$ is $0.002 \Omega$, so the total resistance of seven modules $(105 \mathrm{~V})$ is $0.014 \Omega$. In comparison, battery has $R_{i}=0.06 \Omega$ and output total resistance is $0.5 \Omega$ for nominal voltage $108 \mathrm{~V}$. Internal resistance decline the gain and higher internal resistance decline substantially efficiency of energy storage (battery cca 70-80\% and supercapacitor cca $85-95 \%$ ) [6].

Our experimental power electronics system of $\mathrm{AC} / \mathrm{DC} / \mathrm{AC}$ converter is shown on Fig. 4a. Output voltage of diode ac-dc rectifier $\left(\mathrm{U}_{\mathrm{A}}\right)$ and output voltage of dc-dc converter $\left(\mathrm{U}_{\mathrm{B}}\right)$ are on the Fig. $4 \mathrm{~b}$ as a function of engine speed. Output DC voltage of rectifier is variable in the range 200 to $620 \mathrm{~V}$ and output DC voltage is converted to the constant DC value $570 \mathrm{~V}$ by means of dc-dc converter.

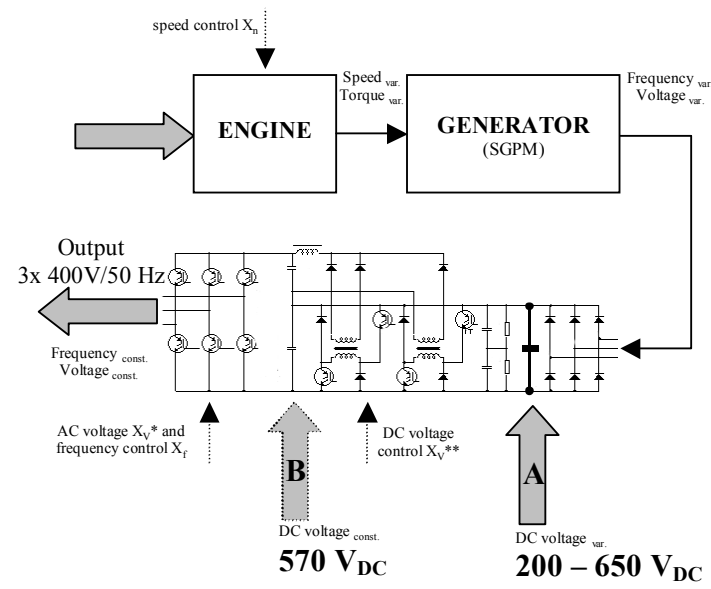

a)

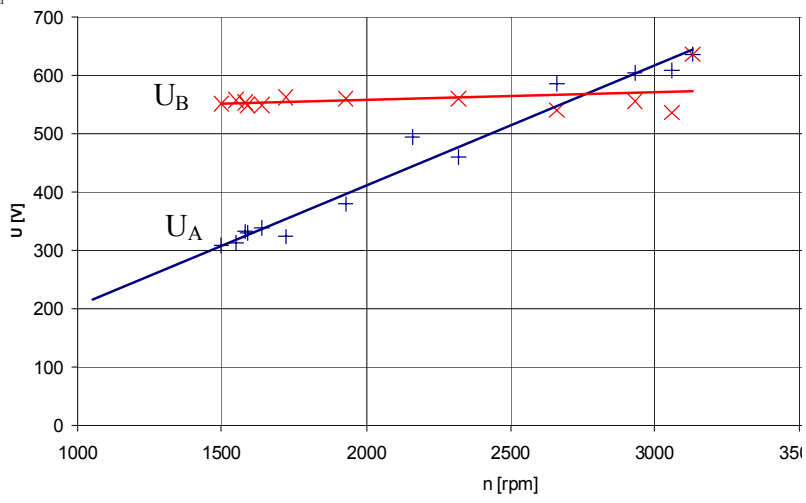

b)

Fig. 4: a) The experimental $\mathrm{AC} / \mathrm{DC} / \mathrm{AC}$ electronics b) Output voltage of $\mathrm{AC} / \mathrm{DC} / \mathrm{AC}$ as $\mathrm{U}=\mathrm{f}(\mathrm{speed})$

In the Fig. 4a the system with two possibilities (A or B) of inserting a bi-directional converter with supercapacitors to the $\mathrm{DC}$ link of $\mathrm{AC} / \mathrm{DC} / \mathrm{AC}$ converter is shown. The fist connection (A) requires DC link of rectifier and the second (B) require DC link of DC/DC converter. Both cases are possible to use for connection with energy buffer according to Fig. 2 .

The first variant $A$ is more advantageous then second $B$ if we focus on converter topology. There is necessary transform supercapacitor voltage from $105 \mathrm{~V}$ to the cca $300 \mathrm{~V}$. This transformation ratio of voltage can be solved by non-isolated bi-directional converter topology which is good at price (Fig. 5a). Second variant $B$ required high transformation ration from $105 \mathrm{~V}$ to $600 \mathrm{~V}$. Full-bridge topology (Fig. 5b) can achieve much better transformer ratio than topology with inductor. On the other hand the shortcoming of full-bridge topology is high number of transistors and thereby the cost of converter is increasing. 


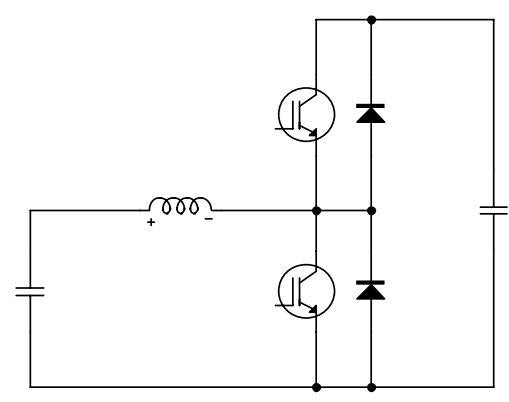

a)

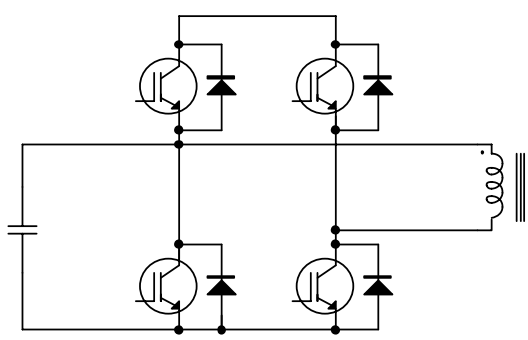

3||$\xi$

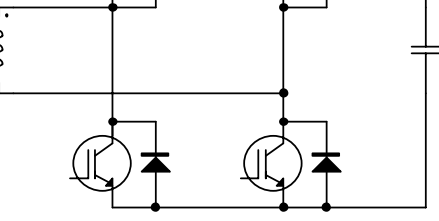

b)

Fig. 5: Bi-directional converters a) inductor b) transformer (full-bridge)

\section{Bi-directional Converter}

Boost mode of bi-directional converters are illustrated by simplified circuit on Fig. 6. More details about step-up mode are elaborated below and [4].

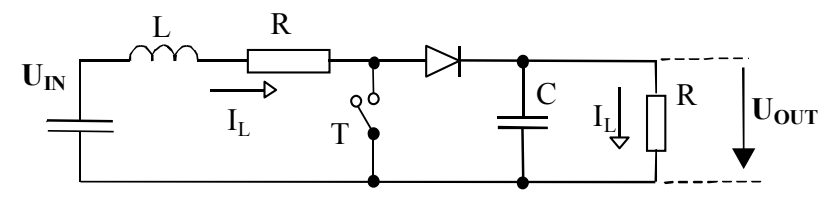

Fig. 6: The simplified circuit model of converter structure of step-up (boost)

$\mathrm{U}_{\mathrm{IN}}$ is an input voltage of converter (or output voltage of supercapacitor too) and $\mathrm{U}_{\text {OUT }}$ is an output voltage of converter which is required by de link of $\mathrm{AC} / \mathrm{DC} / \mathrm{AC}$ converter. Boost mode is described by the linear differential equations (3) for average values. Converter operates in switched mode and the rate of generated voltage is handled by duty ratio $\mathrm{D}=\mathrm{t}_{\mathrm{on}} / \mathrm{T}$, where $\mathrm{t}_{\mathrm{on}}$ is time of switch-on. This value expresses the proportionate time of stapled switch T.

$$
L \dot{I}+R I=U_{I N}-U_{\text {OUT }} \cdot(1-D) ; \quad C \dot{U}_{\text {OUT }}+\frac{1}{R_{L}} U_{\text {OUT }}=I_{L} \cdot(1-D)
$$

The standard forms of the transfer function by LT (Laplace Tran.) and modification to exclude $\mathrm{I}_{\mathrm{L}}(\mathrm{s})$ is:

$$
\begin{aligned}
& F_{U}(s)=\frac{U_{O U T}(s)}{U_{I N}(s)}= \\
& \frac{(1-D)}{C L s^{2}+\left(C R+L R_{L}^{-1}\right) s+R R_{L}^{-1}+(1-D)^{2}}=\frac{R_{L} R^{-1}(1-D)}{T_{1} T_{2} s^{2}+\left(T_{1}+T_{2}\right) s+\left[1+R_{L} R^{-1}(1-D)^{2}\right]}
\end{aligned}
$$

where $T_{1}$ a $T_{2}$ are time constants of input and output circuit of converter [5]. Output transfer function can be described as

$$
\begin{aligned}
& F_{U}(s)=\frac{\frac{R_{L}(1-D)}{R+R_{L}(1-D)^{2}}}{\frac{C R_{L} L}{R+R_{L}(1-D)^{2}} s^{2}+\frac{\left(C R R_{L}+L\right)}{R+R_{L}(1-D)^{2}} s+1}= \\
& =\frac{\frac{(1-D)}{\rho+(1-D)^{2}}}{\frac{C L}{\rho+(1-D)^{2}} s^{2}+\frac{\left(C R+L R_{L}^{-1}\right)}{\rho+(1-D)^{2}} s+1}=\frac{K_{U}}{\tau_{1} \tau_{2} s^{2}+\left(\tau_{1}+\tau_{2}\right) s+1}=\frac{K_{U}}{\frac{p^{2}}{\omega^{2}}+\frac{2 \xi}{\omega} p+1}
\end{aligned}
$$


where converter gain $\mathrm{K}_{\mathrm{U}}$ of voltage control is

$$
K_{U}=\frac{R_{L}(1-D)}{R+R_{L}(1-D)^{2}}=\frac{(1-D)}{\rho+(1-D)^{2}}
$$

and where $\rho$ is the coefficient of common ratio of $R$ and $R_{L}(\rho=R / R Z)$, $\xi$ is ratio of damping. The converter can be described by second order - linear differential equation:

$$
a_{2} \ddot{U}+a_{1} \dot{U}+a_{0} U=b_{0} U_{S}
$$

It is possible to see from the analyses above and from [4] that the dynamic properties could be gauged by the oscillation frequency $\omega$ and coefficient of damping $\xi$. Increasing R causes decrease of converter voltage gain and also converter efficiency. Generally the resistance R damps down the system response. Taking into account the internal voltage source resistance $R_{I}$ the collective resistance $\mathrm{R}_{0}=\mathrm{R}+\mathrm{R}_{\mathrm{I}}$ is the final parameter affecting the system. The output characteristics of a simulation by Matlab-Simulink are on Fig. 7. There are shown $\mathrm{U}_{\mathrm{OUt}}$ and I as a functions of change of duty D from 0.5 to 0.6 in time $20 \mathrm{~ms}$ of two $\mathrm{R}_{\mathrm{L}}=50$ and $200 \Omega$ and there are shown three different values of $\mathrm{R}_{0}$. It is obvious that $R_{L}, R$ and $R_{0}$ have the effect of the output values of voltage and current, respective of the character of transient responses.
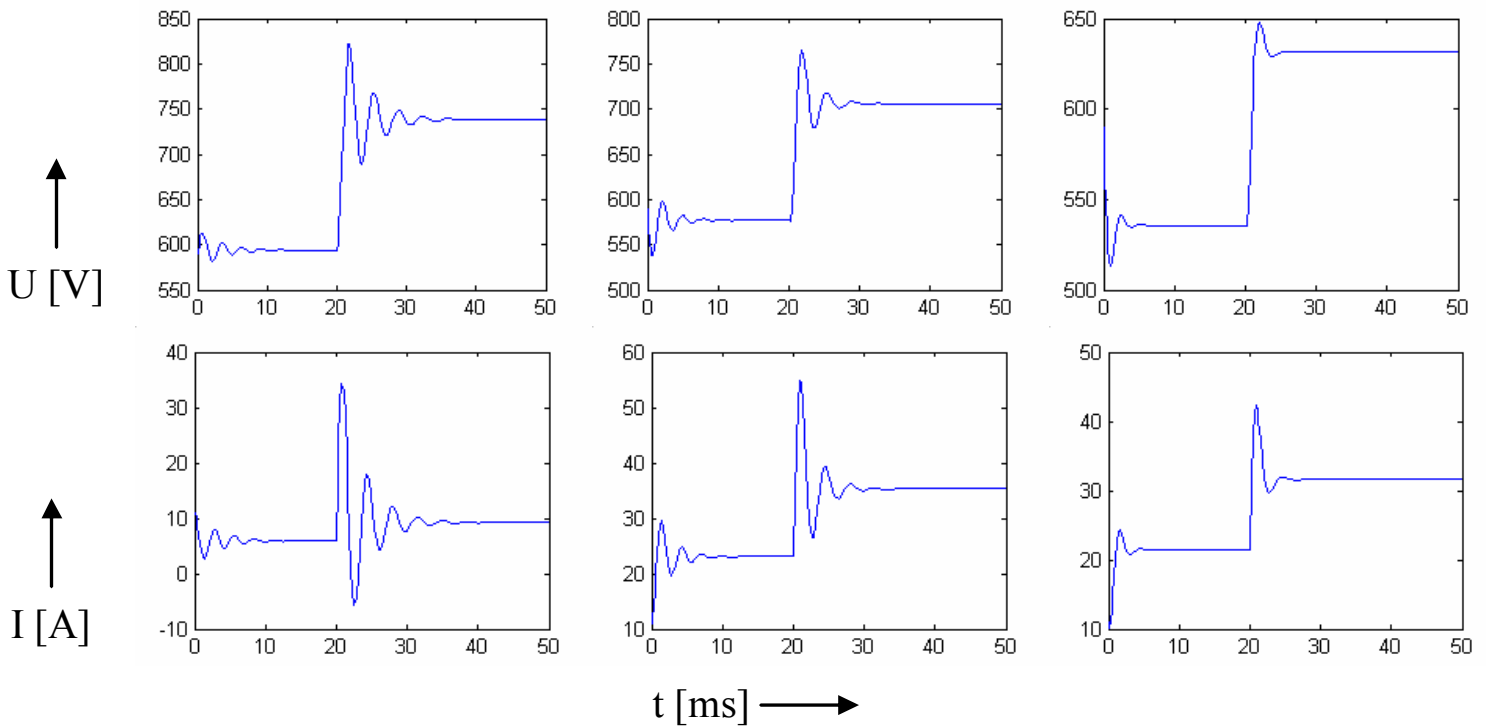

a)

b)

c)

Fig. 7: Converter transient responses of duty $D$ from 0.5 to 0.6 a) $R=0.5 \Omega, R_{0}=0 \Omega, R_{L}=200 \Omega$; b) $\mathrm{R}=0.5 \Omega, \mathrm{R}_{0}=0 \Omega, \mathrm{R}_{\mathrm{L}}=50 \Omega$; c) $\mathrm{R}=0.5 \Omega, \mathrm{R}_{0}=1 \Omega, \mathrm{R}_{\mathrm{L}}=50 \Omega$

\section{Design of Bi-directional converter}

The current EGS experimental model with supercapacitor buffer is designed with a bi-directional DC/DC converter according to the circuit topology introduced on fig. 5a. Buffer of supercapacitors includes $7 \mathrm{x} 15 \mathrm{~V} 58 \mathrm{~F}$ supercapacitors which are connected in series with output voltage $105 \mathrm{~V}$. Such buffer can accumulate energy as much as $34 \mathrm{~kJ}$ (eq. 2). The flow of energy from or to buffer must be controlled according to requirements of power management. The converter operates either in Boost mode during energy delivering from buffer to dc line (Fig. 8b) or in Buck during buffer charging (8a).

Buck mode has a output voltage $\mathrm{U}_{\text {OUT }}$ is less than the input voltage $\mathrm{U}_{\mathrm{IN}}$ and output voltage can be calculated by following formula:

$$
U_{\text {OUT }}=D \cdot U_{I N}
$$

where $\mathrm{D}=\mathrm{t}_{\mathrm{ON}} / \mathrm{T}$. As mentioned above, input voltage is variable in the range $300-600 \mathrm{~V}$ (see Fig. 6, 8). 


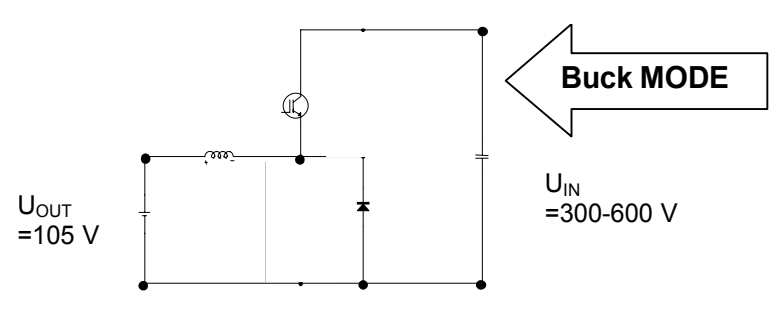

a)

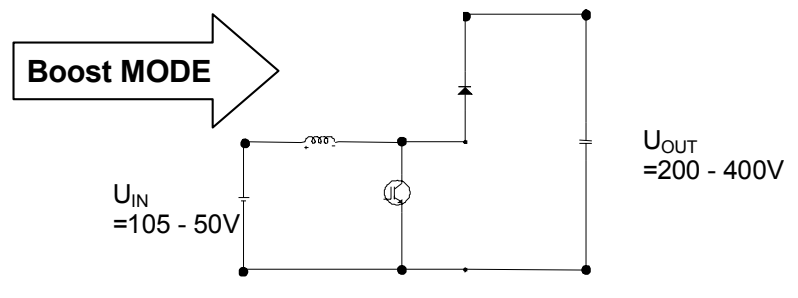

b)

Fig. 8: Topology of bi-directional converter of a) Buck mode b) Boost mode

The induction $\mathrm{L}$ of inductor must be higher than we obtain from formula

$$
L_{\min }=\frac{D \cdot U_{I N} \cdot(1-D)}{2 \cdot f \cdot \Delta i_{L}}
$$

to be achieved continuous operating mode characterized by continuous inductor current [6]. $\Delta \mathrm{i}_{\mathrm{L}}$ is a ripple inductor current that is maximally acceptable by supercapacitors. Output voltage ripple can be decreased by value of capacity and equation 10 shows the calculation of minimum capacity which is required for our limit of $\Delta \mathrm{U}_{\text {OUT }}$.

$$
C_{\min }=\frac{D \cdot(1-D)}{16 \cdot f^{2} \cdot L} \cdot \frac{U_{I N}}{\Delta U_{\text {OUT }}}
$$

Table I contains calculation results of inductions and capacities as a functions of variable input voltage for frequency $15 \mathrm{kHz}$.

Table I: Buck mode

\begin{tabular}{|l||l|l|l|l|l|l|}
\hline $\mathbf{U}_{\text {in }}$ & $\mathbf{3 0 0}$ & $\mathbf{3 5 0}$ & $\mathbf{4 0 0}$ & $\mathbf{4 5 0}$ & $\mathbf{5 0 0}$ & $\mathbf{6 0 0}$ \\
\hline $\mathrm{U}_{\text {out }}$ & 105 & 105 & 105 & 105 & 105 & 105 \\
\hline $\mathrm{D}$ & 0,33 & 0,29 & 0,25 & 0,22 & 0,20 & 0,17 \\
\hline $\mathrm{f}$ & 15000 & 15000 & 15000 & 15000 & 15000 & 15000 \\
\hline & & & & & & \\
\hline $\mathrm{I}$ & 10,00 & 10,00 & 10,00 & 10,00 & 10,00 & 10,00 \\
\hline$\Delta \mathrm{i}_{\mathrm{L}}$ & 2 & 2 & 2 & 2 & 2 & 2 \\
\hline$\Delta \mathrm{U}_{\text {OUT }}$ & 10 & 10 & 10 & 10 & 10 & 10 \\
\hline & & & & & & \\
\hline $\mathbf{L}_{\min }$ & $\mathbf{1 , 1 1 E - 0 3}$ & $\mathbf{1 , 1 9 E - 0 3}$ & $\mathbf{1 , 2 5 E - 0 3}$ & $\mathbf{1 , 3 0 E - 0 3}$ & $\mathbf{1 , 3 3 E - 0 3}$ & $\mathbf{1 , 3 9 E - 0 3}$ \\
\hline $\mathbf{C}_{\min }$ & $\mathbf{1 , 7 E - 0 6}$ & $\mathbf{1 , 7 E - 0 6}$ & $\mathbf{1 , 7 E - 0 6}$ & $\mathbf{1 , 7 E - 0 6}$ & $\mathbf{1 , 7 E - 0 6}$ & $\mathbf{1 , 7 E - 0 6}$ \\
\hline
\end{tabular}

Boost mode is more complicated in comparison with buck mode of our application of EGS. Both voltage $\left(\mathrm{U}_{\mathrm{IN}}\right.$ and $\left.\mathrm{U}_{\mathrm{OUT}}\right)$ are variable and the output voltage must be controlled to achieve constant voltage in the range from 200 to $400 \mathrm{~V}$. The output voltage depends on engine speed (fig. $4 \mathrm{~b}$ ) and voltage state of supercapacitor $(105-50 \mathrm{~V})$. Output voltage is calculated according to follow formula

$$
U_{\text {OUT }}=\frac{U_{I N}}{1-D}
$$

The control strategies must respond the output voltage of uncontrolled rectifier (fig. 4a, topology A). Transfer of energy is controlled since a change of load appears. These changes are caused by changing of engine speed from lower to higher. At the time of speed change the engine-generator is set unload and all energy flows from supercapacitors.

Table II shows recommended values of inductor similarly as in the Table I. Based on Table I and Table II the value of the $\mathrm{L}$ is selected to be approximately $2 \mathrm{mH}$. 
Table II: Boost mode

\begin{tabular}{|l||l|l|l|l|l|l|}
\hline $\mathbf{U}_{\text {in }}$ & $\mathbf{5 0}$ & $\mathbf{1 0 0}$ & $\mathbf{5 0}$ & $\mathbf{1 0 0}$ & $\mathbf{5 0}$ & $\mathbf{1 0 0}$ \\
\hline $\mathbf{U}_{\text {out }}$ & $\mathbf{3 0 0}$ & $\mathbf{3 0 0}$ & $\mathbf{4 0 0}$ & $\mathbf{4 0 0}$ & $\mathbf{5 0 0}$ & $\mathbf{5 0 0}$ \\
\hline $\mathrm{D}$ & 0,83 & 0,67 & 0,88 & 0,75 & 0,90 & 0,80 \\
\hline $\mathrm{f}$ & 15000 & 15000 & 15000 & 15000 & 15000 & 15000 \\
\hline & & & & & & \\
\hline $\mathrm{I}$ & 20,00 & 20,00 & 15,00 & 15,00 & 12,00 & 12,00 \\
\hline$\Delta \mathrm{i}_{\mathrm{L}}$ & 2 & 2 & 2 & 2 & 2 & 2 \\
\hline$\Delta \mathrm{U}_{\text {OUT }}$ & 10 & 10 & 10 & 10 & 10 & 10 \\
\hline & & & & & & \\
\hline Lmin & $\mathbf{6 , 9 4 E - 0 4}$ & $\mathbf{1 , 1 1 E - 0 3}$ & $\mathbf{7 , 2 9 E - 0 4}$ & $\mathbf{1 , 2 5 E - 0 3}$ & $\mathbf{7 , 5 0 E - 0 4}$ & $\mathbf{1 , 3 3 E - 0 3}$ \\
\hline
\end{tabular}

The design of the inductor and its magnetic circuit is very important. The requirements of converters are resumed below. To summarize the converters are $6 \mathrm{~kW}$, output in current Boost mode is $20 \mathrm{~A}$ with $\Delta \mathrm{i}_{\mathrm{L}}<2 \mathrm{~A}$, frequency $15 \mathrm{kHz}$ and induction of the converter must be about $2 \mathrm{mH}$. Magnetic circuit was chosen as folows: $U$ core; $1924 \mathrm{~mm}^{2}(37 \times 52 \mathrm{~mm})$ and profile $\mathrm{a}=19 \mathrm{~mm} ; \mathrm{B}_{\mathrm{Max}}=0.3 \mathrm{~T}$; permeability $\mu_{\mathrm{rFE}}=1000$ a path length $1_{\mathrm{FE}}=0.28 \mathrm{~m}$.

Number of inductor windings is calculated by the equation 12 [6]:

$$
N=\frac{L \cdot I_{\max }}{B_{\max } \cdot S_{F E}}=\frac{L \cdot I_{\max }}{B_{\max } \cdot a^{2}}=\frac{2 m \cdot 20}{0.3 \cdot 3.61 \cdot 10^{-4}}=370
$$

Airgap is calculated by:

$$
l_{v}=\frac{L \cdot \mu_{o} \cdot I_{\max }^{2}}{B_{\text {max }}^{2} \cdot S_{F E}}-\frac{l_{F E}}{\mu_{r F E}}=\frac{2.10^{-3} \cdot 1.256 \cdot 10^{-6} \cdot 20^{2}}{0.3^{2} \cdot 3.61 \cdot 10^{-4}}-\frac{0.28}{1000}=0.003[\mathrm{~m}]
$$

The Fig. 9a shows results of measurement of inductance $L$ as a function of frequency. This measurement was made for low value of current (by RLC meter). It is possible to see that $\mathrm{L}$ is constant. The effect of airgap on $\mathrm{L}$ is also demonstrated for its value $1 \mathrm{~d}=1.2 \mathrm{~mm}$. If $\mathrm{d}=0$ than $\mathrm{L}$ will be already supersaturated for a low value of current. If $d>>1_{\mathrm{FE}} / \mu_{\mathrm{rFE}}$ than behavior of $\mathrm{L}$ will be the same as $\mathrm{L}$ without magnetic core. If $\mathrm{d} \approx 1_{\mathrm{FE}} / \mu_{\mathrm{rFE}}$ than the value of $\mathrm{L}$ will be also useful but it will depend on current $\mathrm{L}=\mathrm{f}(\mathrm{I})$. Fig. $9 \mathrm{~b}$ illustrates the test results of $\mathrm{L}$ as a function of $\mathrm{I}$. The characteristics $(\mathrm{d}=0)$ of Fig. $9 \mathrm{~b}$ show a well know relation of saturation with low current. The effect of saturation can be diminished by airgap but than $\mathrm{L}$ has worse steepness of V-A characteristic.



a)

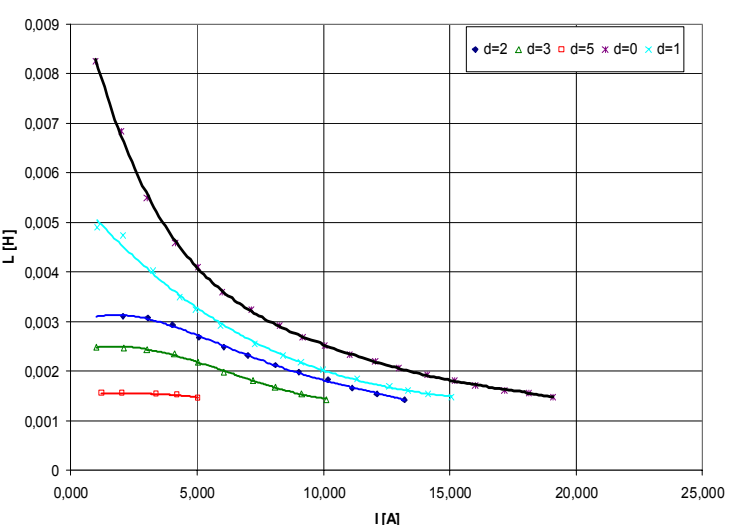

b)

Fig. 9: a) $\mathrm{L}$ as a function of frequency and airgap b) $\mathrm{L}$ as a function of current ( $\sin 50 \mathrm{~Hz})$

The test and measurement of $\mathrm{L}$ as effect of value frequency of higher current from 1 to $20 \mathrm{~A}$ requires such a quality of instruments which is not provided by our recent equipment. In the fig. 10 is possible 
to see the results of $\mathrm{L}$ with PWM signal $(\mathrm{D}=0.5$ and $\mathrm{f}=50 \mathrm{~Hz}$ ). The measurements are quite complex and demanding. It is not possible to eliminate the problem of cress factor during measurements.

Fig. 10b shows the oscilloscope records of the test of $\mathrm{L}$ with PWM exciting and on the figure you can see the problem with cress factor which is applied during measurement.



a)

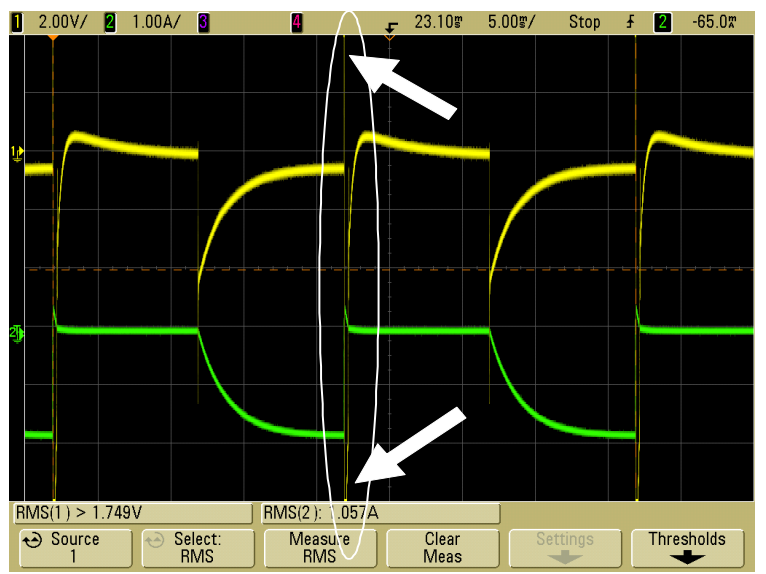

b)

Fig. 10: a) $\mathrm{L}$ as a function of current $(\mathrm{PWM} ; 50 \mathrm{~Hz}) \mathrm{b}$ ) Cress effect of measurement with PWM signal

The final value of $R$ is $0.2 \Omega$. The results of boost mode measurement with a variable input voltage as a function of duty is illustrated in the Fig. 11a. The simulation results and formulas that are shown above are correct and test results confirm its accuracy. On the Fig. 11b is shown the output efficiency of bi-directional converters during boost mode.

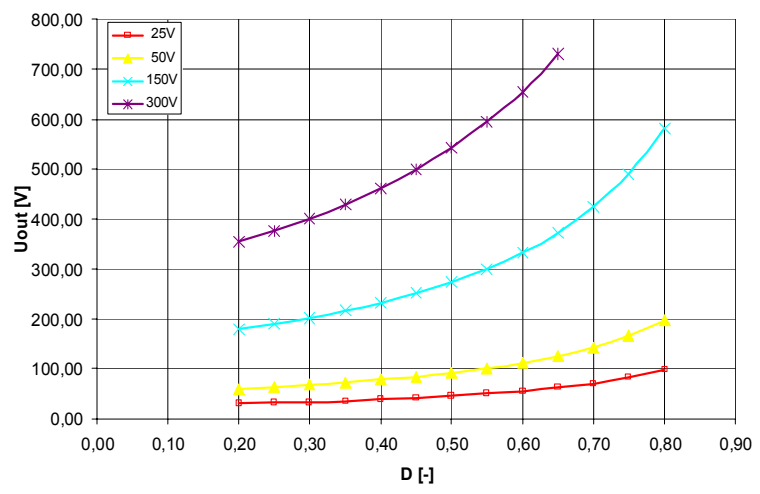

a)

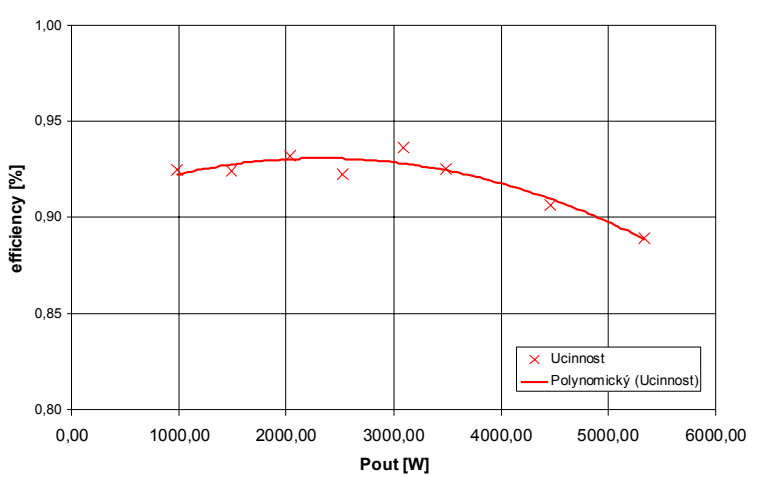

b)

Fig. 11: a) $U_{\text {OUT }}$ of converter as a function of $D$ and $U_{\text {IN }}$ (boost) b) Efficiency of converter (boost)

\section{Feed-back control of Bi-directional converters}

Control mechanism can be used as feed-forward. The scheme of feed-forward is shown in Fig. 12a. $U_{P}$ is required output voltage, $\mathrm{U}_{\mathrm{IN}}$ is voltage of accumulator and $\mathrm{D}$ is duty cycle.

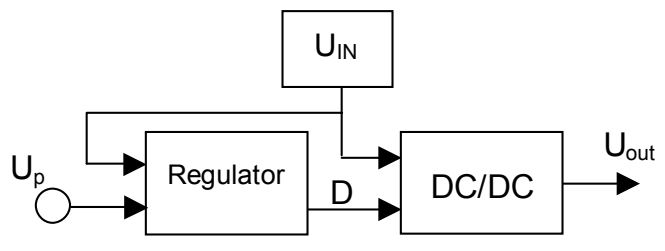

a)

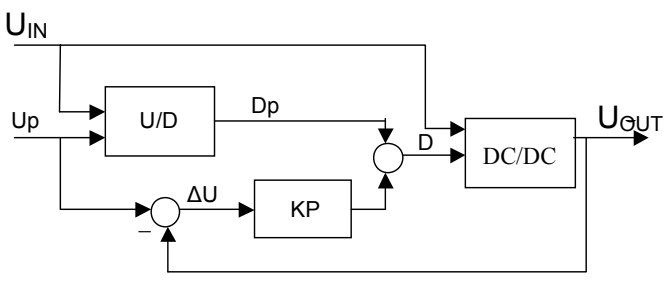

b)

Fig. 12: a) Feed-forward control of DC/DC converter b) Feed-back control of DC/DC converter

Feed-forward control does not allow to control transient process and control system has no information about actual output voltage of DC/DC converter. Sudden load change of EGS can produce 
voltage decrease (increase) and system cannot respond to this load change. Fig. 12b shows feed-back control variant with proportional controller. Control voltage error $e$ can be expressed by equation

$$
e=\Delta U=U_{p}-U_{\text {OUT }}
$$

Voltage deviation can be solved as duty change D. Equation (11) shows resulting equality between voltage deviation and duty deviation. Where $\rho$ is ratio of $R_{i}$ and $R_{L} . R_{i}$ is internal resistance of DC/DC converter and $\mathrm{R}_{\mathrm{L}}$ is value of resistor load.

$$
D=1+\frac{\rho}{(1-D)}-\frac{U_{I N}}{U_{P}}
$$

As mentioned above on Fig. 7, where the results of simulation of bi-directional converters were shown and especially their dynamic behavior. The analyses of dynamic behaviors are dependent on internal resistance $R$ of energy buffer (supercapacitors) and internal resistance $\mathrm{R}_{\mathrm{IN}}$ of Bi-directional converters. The experimental model of control system of our Bi-directional converter was implemented into FPGA circuit. Details about our FPGA realization are shown below.

\section{FPGA realization}

The feedback-based control system consists of two basic elements: a control logic represented by Field Programmable Gate Array (FPGA) device and two 14-bits AD converters used to acquire current values of Up and Uout. The control logic transfers the voltage error e expressed by equation (14) to pulse-width modulated (PWM) signal.

Concept of using FPGA device was chosen because of its flexibility, ability to improve or extend already designed control system and also because of its reliability on the contrary of the similar design based on discrete components. Developed control logic was implemented into device Xilinx Spartan $3 \mathrm{E}$ providing external basic clock up to $100 \mathrm{MHz}$. Design is stored in external FLASH memory and can be reprogrammed even during the time when FPGA is working. Spartan 3E chip is a part of a development board made by Digilent which includes among others also two-channel 14-bits AD converter Linear Technology LTC1407A-1 linked to an input programmable scaling pre-amplifier LTC6912-1.

The core of the control logic is the PWM module. It generates pulse signal with duty cycle of D related to difference of input voltages designated e depicted on fig. 13. The control logic also contains auxiliary PicoBlaze 8-bit microcontroller which is embedded into the FPGA design and which communicates to AD converters and other peripherals using serial bus SPI (Serial Peripheral Interface).

\section{The verification of EGS concept with energy buffer}

On Fig. 14 it is possible to see the experimental verification of the EGS concept with energy buffer as well as feed-back control of the speed. The yellow curve $(\mathrm{CH} 1)$ is the same as in Figures $10 \& 11$ and shows the current of the rectifier. The red curve $(\mathrm{CH} 4)$ shows the engine speed. The output dc voltage is shown by the green curve ( $\mathrm{CH} 2)$, while the output power is shown as the violet curve (MATH) which is calculated from the output dc voltage and dc current. In time interval $\mathrm{T} 1$ the system was loaded with $1 \mathrm{~kW}$ at $1500 \mathrm{rpm}$. In time interval T2 the power load was changed from $1 \mathrm{~kW}$ to $5.06 \mathrm{~kW}$. During this time $(2,28 \mathrm{~s})$ the transition takes place and power is extracted from the energy storage element. Time interval T3 shows the steady-state condition of the system. It is possible to see that the system is now capable of handling the power load change combined with the feed-back control of the engine speed (set at an optimal speed of the diesel engine).

This proves the feasibility of the EGS with variable speed of engine concept. 


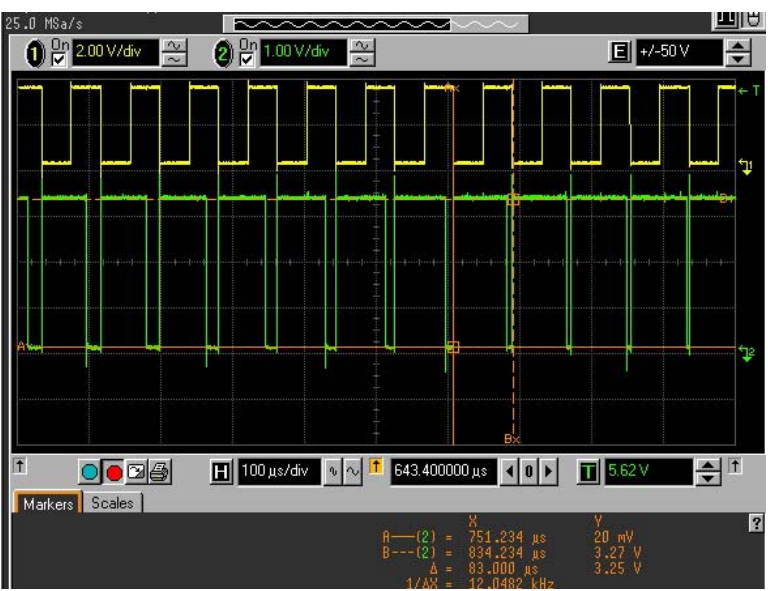

Fig. 13: Signals generated by PWM module. Upper signal (yellow) is a clock reference of pulsed signal $\mathrm{f}_{0}=12 \mathrm{kHz}$. Lower signal (green) is a PWM signal modulated by $50 \mathrm{~Hz}$ sinus signal

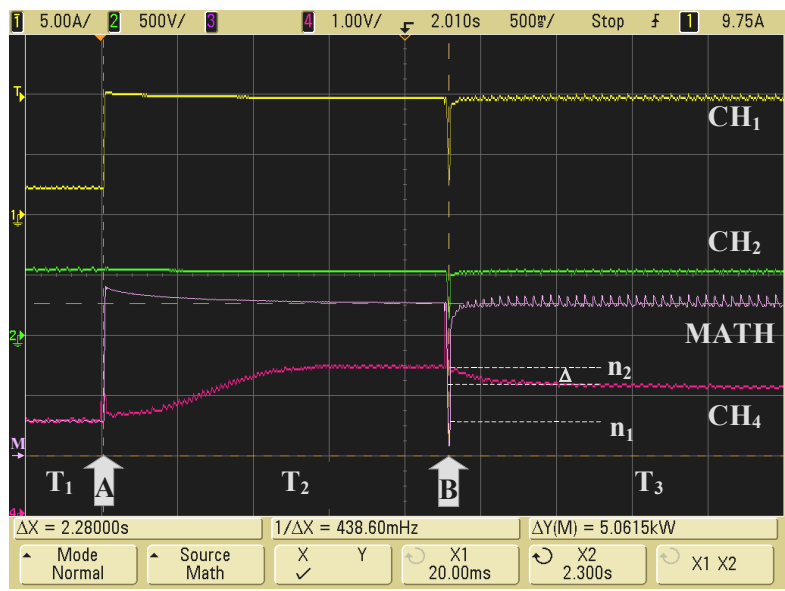

Fig. 14: The verification of EGS concept with energy buffer $(\mathrm{CH} 1 \ldots 1 \mathrm{~A} / \mathrm{div} ; \mathrm{CH} 2 \ldots 500 \mathrm{~V} / \mathrm{div} ; \mathrm{CH} 4 \ldots 1000$ $\mathrm{rpm} / \mathrm{div} ; \mathrm{MATH} . . .2 \mathrm{~kW} / \mathrm{div})$

\section{Conclusion}

The analysis and tests of EGS with variable speed of engine has shown that the bad dynamical properties of the system during load changing. Dynamic behavior of EGS with variable speed of engine can be considerably improved by implementing power electronic converters with an energy buffer. Two different ways of connecting the buffer with a DC-DC converter were suggested. By connecting the buffer to the link of the rectifier a simple buck/boost converter can be used. The design of this converter and its inductance is demonstrated in the paper. By connecting the buffer to the link of an inverter the converter is designed for a higher voltage and a topology with transformer has to be used. System of EGS according to Fig. 2 was with the energy buffer was verified and resulting dynamic behaviour was satisfactory.

\section{References}

[1] Tolbert, L.,M.- Peterson, W., A.- White, C., P. - Theiss, T.,J.- Scudiere, M.,B. “A bi-directional dc-dc converter with minimum energy storage elements," in Conf. Rec. IEEE IAS Meeting, 2002, pp. 1572-1577.

[2] Leuchter, J., Rerucha, V., Bauer, P.: "Dynamic Behavior of Mobile Generator Set with Variable Speed and Diesel Engine,“ IEEE Power Electronics Specialist Conference 2007, Orlando, June 2007.

[3] Leuchter, J.- Kurka, O.- Bauer, P. “Mobile Electrical-generator Sets,” Power Systems Design EUROPE Transl., Germany, vol. 3, Issue 1, ISSN: 1613-6365, January/Feruary 2006, pp. 40-44.

[4] Řerucha, V. - Krupka, Z. - Kurka O.-and Leuchter, J. "The Analyses of dynamic Behavior of EGS," Research Study of the project GAČR 102/03/0795, University of Defence, 2003. [in Czech]

[5] Maga, D.-Hart'anský, R.; "Numerické riešenia,” in book of University of Defence, 2006. [in Slovak] ISBN 80-7231-130-1.

[6] Patocka,M.- Hutak, P.- Vorel, P. “Ultracapacitors in Electromobiles,” in Conf. EPVE, 2002, pp. 139-144.

[7] http://www.ecom.cz

[8] R. K. Járdan, I. Nagy, A. Olasz, “Time Domain Control of a Power Quality Conditioning System, "

Proceedings of the international conference EDPE 2005; Croatia, 2005

[9] J.Dudrik, P.Bauer: DC Source for Arc Welding with Soft-Switching Current-Mode Controlled DC-DC Converter, International Review of Electrical Engineering (IREE), March-April 2006, ISSN: $1827-6600$ pp. $162-170$

[10] Lettl, J.: Employment of Power Semiconductor Converters in Hybrid Drives. In Proceedings of the WSEAS International Conferences: 6th International Conference on Power Systems. WSEAS Press, 2006, s. 2. ISBN 960-8457-53-X. 